\title{
Prognostic implications of thymidylate synthase gene polymorphisms in patients with advanced small bowel adenocarcinoma treated with first-line fluoropyrimidine-based chemotherapy
}

\author{
HO-YOUNG YHIM ${ }^{1,2}$, SANG-HEE CHO ${ }^{3}$, SAM YONG KIM ${ }^{4}$, IN SUNG CHO ${ }^{5}$, KYU TAEK LEE ${ }^{6}$, \\ WON SUP LEE ${ }^{7}$, SOON IL LEE ${ }^{8}$, MOO RIM PARK $^{9}$, SANG-GON PARK $^{10}$, HYE-SUK HAN $^{11}$, \\ YOON SEOK CHOI ${ }^{4}$, IK-JOO CHUNG ${ }^{3}$, HYUN-JEONG SHIM ${ }^{3}$, NA-RI LEE ${ }^{1,2}$, \\ EUN-KEE SONG ${ }^{1,2}$, HEE SUN KIM ${ }^{12}$ and CHANG-YEOL YIM ${ }^{1,2}$
}

\begin{abstract}
${ }^{1}$ Department of Internal Medicine, Chonbuk National University Medical School, Jeonju; ${ }^{2}$ Research Institute of Clinical Medicine of Chonbuk National University-Biomedical Research Institute of Chonbuk National University Hospital, Jeonju;

${ }^{3}$ Department of Internal Medicine, Chonnam National University Medical School, Jeollanam-do; ${ }^{4}$ Department of Internal

Medicine, Chungnam National University College of Medicine, Daejeon; ${ }^{5}$ Department of Internal Medicine,

Eulji University Hospital, Daejeon; ${ }^{6}$ Department of Internal Medicine, Soonchunhyang University Cheonan Hospital, Cheonan;

${ }^{7}$ Department of Internal Medicine, Gyeongsang National University School of Medicine, Jinju; ${ }^{8}$ Department of Medicine,

Dankook University Hospital, Cheonan; ${ }^{9}$ Department of Internal Medicine, Wonkwang University School of Medicine, Iksan;

${ }^{10}$ Department of Internal Medicine, Chosun University Hospital, Gwangju; ${ }^{11}$ Department of Internal Medicine,

Chungbuk National University College of Medicine, Cheongju; ${ }^{12}$ Department of Nursing,

Wonkwang University School of Medicine, Iksan, Republic of Korea
\end{abstract}

Received March 18,2015; Accepted April 17, 2015

DOI: 10.3892/or.2015.3954

\begin{abstract}
Thymidylate synthase (TS) gene polymorphisms such as tandem repeat (TR) polymorphisms and single-nucleotide polymorphisms (SNPs) affect transcriptional efficiency of the TS gene and may be prognostic markers for fluoropyrimidine-based therapy in various gastrointestinal cancers. However, data for TS polymorphisms on clinical outcomes in advanced small bowel adenocarcinoma (SBA) are limited. We retrospectively enrolled 58 locally advanced/metastatic SBA patients treated with first-line fluoropyrimidine-based chemo-
\end{abstract}

Correspondence to: Professor Chang-Yeol Yim, Department of Internal Medicine, Chonbuk National University Medical School, 20, Geonji-ro, Deokjin-gu, Jeonju, 561-712, Republic of Korea E-mail: cyyim@jbnu.ac.kr

Abbreviations: CEA, carcinoembryonic antigen; CRC, colorectal cancer; CT, computed tomography; ECOG, Eastern Cooperative Oncology Group; IHC, immunohistochemistry; ORR, overall response rate; OS, overall survival; $\mathrm{PCR}$, polymerase chain reaction; PFS, progression-free survival; RECIST, Response Evaluation Criteria in Solid Tumors; SBA, small bowel adenocarcinoma; SNP, single-nucleotide polymorphism; TR, tandem repeat; TS, thymidylate synthase; UTR, untranslated region; 5-FU, 5-fluorouracil

Key words: genotype, polymorphism, prognosis, small bowel adenocarcinoma, thymidylate synthase therapy and analyzed the relationship between $T S$ genotypes and clinical outcomes in 30 patients who were available for tumor tissue. Based on TR polymorphisms and a $\mathrm{G}>\mathrm{C}$ SNP in the promoter region of the $T S$ gene, $74 \%$ of patients had high TS expression genotypes (2R/3RG, 3RG/3RC, 3RG/3RG); the remainder had low TS expression genotypes $(2 \mathrm{R} / 2 \mathrm{R}, 2 \mathrm{R} / 3 \mathrm{RC}$, 3RC/3RC). After a median follow-up of 48.8 months, median progression-free survival (PFS) and overall survival (OS) in all patients were 6.0 and 11.3 months, respectively. However, patients with low TS expression genotypes had better median PFS (12.8 vs. 4.3 months, $\mathrm{P}=0.027)$ and $\mathrm{OS}(28.8$ vs. 8.9 months, $\mathrm{P}=0.025)$ than those with high TS expression genotypes. In multivariate analysis, poor Eastern Cooperative Oncology Group performance status [hazard ratio (HR), 2.85; 95\% CI, 1.02-7.93] and high TS expression genotypes (HR, 3.49; 95\% CI, 1.13-10.78) were independent prognostic factors for worse OS. Therefore, TS genotypes, based on a G>C SNP in the TR sequence of the TS gene, may be a useful biomarker for predicting outcomes for fluoropyrimidine-based chemotherapy in patients with locally advanced/metastatic SBA.

\section{Introduction}

Small bowel adenocarcinoma (SBA) is a rare malignancy, accounting for $<5 \%$ of all gastrointestinal cancers, and is associated with a poor prognosis (1). Standard chemotherapeutic regimens for SBA have not been established due to the lack of prospective randomized studies. Fluoropyrimidines, 
including 5-fluorouracil (5-FU) and capecitabine, have been the most commonly studied cytotoxic chemotherapeutic agents for advanced SBA. Fluoropyrimidines in combination with oxaliplatin, irinotecan, or doxorubicin/mitomycin have shown clinical benefits in small phase II studies (2-5). In addition, several retrospective studies have revealed that pretreatment performance status (6-8), primary tumor site (7), and serum carcinoembryonic antigen (CEA) level $(6,7)$ might have a prognostic role in patients receiving fluoropyrimidinebased chemotherapy. However, molecular markers reflective of tumor biology and predictive of chemotherapeutic sensitivity/resistance in patients with advanced SBA are lacking. Such molecular markers predicting treatment response will help physicians to select treatment strategies for this rare disease.

The antitumor effect of fluoropyrimidines has been associated with competitive inhibition of thymidylate synthase (TS) $(9,10)$. Preclinical studies have shown that increased TS expression is associated with resistance to 5-FU in cancer cell lines $(11,12)$. Subsequent clinical studies have demonstrated that TS expression may play an important role in determining tumor sensitivity to fluoropyrimidines (13-15). Therefore, the TS tissue level may modulate the efficacy of fluoropyrimidine therapy against tumor cells. Polymorphisms within the 5'-untranslated region (UTR) of the TS gene have been shown to be important in controlling TS expression. Polymorphisms in the 5'-UTR regulate $T S$ transcription and have been suggested to be potential predictors of response to 5-FU chemotherapy (16-18). Two main polymorphisms in the 5'-UTR that modulate $T S$ transcription have been described: the tandem repeat (TR) polymorphism and $\mathrm{G}>\mathrm{C}$ single-nucleotide polymorphism (SNP). The TR polymorphism comprises double (2R) or triple (3R) repeats of a 28-base pair (bp) sequence in the 5'-UTR $(16,17)$. This polymorphism is associated with TS gene transcription efficiency, which is lower with the double repeat than with the triple repeat (16). The G>C SNP in the second repeat of the $3 \mathrm{R}$ alleles is associated with decreased transcriptional activity of the $3 \mathrm{R}$ alleles (18). Consequently, the transcriptional efficiency of $3 R$ alleles with the $G>C$ substitution (3RC) is similar to that of $2 \mathrm{R}$ alleles. Recently, several studies have demonstrated that TS SNP status might be associated with clinical outcomes in colorectal cancer (CRC) patients receiving 5-FU-based chemotherapy or preoperative chemoradiotherapy (19-22). However, the prognostic and predictive relevance of $T S$ gene polymorphisms in SBA have not yet been investigated. Thus, in the present study, we aimed to evaluate the prognostic implications of polymorphisms in the 5'-UTR of the TS gene on treatment outcomes in patients with locally advanced/metastatic SBA receiving fluoropyrimidine-based chemotherapy.

\section{Materials and methods}

Study design and patient population. We performed a multicenter, retrospective cohort study of patients with pathologically confirmed locally advanced (unresectable or incompletely resected) or metastatic SBA who received $\geq 1$ cycle of first-line fluoropyrimidine-based chemotherapy at 10 medical centers in Korea between Jan 2003 and Dec 2012. Patients with localized or completely resected disease and those who received front-line treatment with non-fluoropyrimidine-containing chemotherapy were excluded. Patients with cancer of the ampullar of Vater or periampullary cancer were also excluded. Prior history of chemotherapy for metastatic disease was not allowed, but previous use of fluoropyrimidines was permitted if fluoropyrimidines were used as adjuvant therapy and the interval between completion of adjuvant therapy and recurrence of disease was more than 6 months. Data were collected using study-specific case record forms from participating institutions. Collected data included patient demographics, tumor characteristics, first-line chemotherapy regimens and dose intensities, response to first-line therapy, progression-free survival (PFS) and overall survival (OS). The study protocol was reviewed and approved by the institutional review board at each participating institution, and the study was conducted in accordance with the recommendations of the Declaration of Helsinki for biomedical research involving human subjects.

Treatment and outcome measurement. First-line chemotherapy consisted of the following 4 regimens: the cisplatin and fluoropyrimidines (FP) regimen, cisplatin $\left(75 \mathrm{mg} / \mathrm{m}^{2}\right)$ day 1 plus infusional 5 -FU $\left(1,000 \mathrm{mg} / \mathrm{m}^{2}\right)$ for 4 consecutive days or oral capecitabine $\left(1,000 \mathrm{mg} / \mathrm{m}^{2}\right.$ twice a day) for 14 consecutive days every 3 weeks; the FOLFOX regimen, 2-h infusion of oxaliplatin $\left(85\right.$ or $100 \mathrm{mg} / \mathrm{m}^{2}$ ) on day 1 plus folinic acid $\left(200 \mathrm{mg} / \mathrm{m}^{2}\right)$ and bolus $5-\mathrm{FU}\left(400 \mathrm{mg} / \mathrm{m}^{2}\right)$ followed by a $46-\mathrm{h}$ infusion of 5 -FU $\left(2,400 \mathrm{mg} / \mathrm{m}^{2}\right)$ every 2 weeks; the FOLFIRI regimen, $90-\mathrm{min}$ infusion of irinotecan $\left(180 \mathrm{mg} / \mathrm{m}^{2}\right)$ on day 1 plus folinic acid $\left(200 \mathrm{mg} / \mathrm{m}^{2}\right)$ and bolus 5 -FU $\left(400 \mathrm{mg} / \mathrm{m}^{2}\right)$ followed by a $46-\mathrm{h}$ infusion of 5 -FU $\left(2,400 \mathrm{mg} / \mathrm{m}^{2}\right)$ every 2 weeks; fluoropyrimidine alone, protracted venous infusion of 5-FU using a portable pump at a dose of $300 \mathrm{mg} / \mathrm{m}^{2} /$ day or oral capecitabine $1,250 \mathrm{mg} / \mathrm{m}^{2}$ twice daily on day 1 through 14 every 3 weeks. The treatment regimen was selected at the discretion of the treating physician. First-line chemotherapy was discontinued in patients who progressed during treatment or experienced unacceptable toxicities. Management of adverse events and subsequent dose reduction of chemotherapeutic agents was performed at the discretion of the physician based on hematologic or non-hematologic adverse events. Tumor responses were assessed in patients with measurable lesions using contrast-enhanced computed tomography (CT) every three or four cycles or earlier when signs of progression were evident. Objective tumor response was evaluated using the Response Evaluation Criteria in Solid Tumors (RECIST) criteria (23). PFS and OS were calculated from the day of diagnosis until progression, death or last follow-up as appropriate.

Immunohistochemistry (IHC) for TS. TS expression was analyzed in 3- $\mu \mathrm{m}$-thick sections from pretreatment formalinfixed paraffin-embedded (FFPE) tissues. Sections were deparaffinized and subjected to heat-induced antigen retrieval by microwaving in Tris-EDTA buffer (EnVision FLEX High $\mathrm{pH}$; Dako, Glostrup, Denmark) for $15 \mathrm{~min}$. Tissue sections were incubated with $3 \%$ hydrogen peroxide for $10 \mathrm{~min}$ to inhibit endogenous peroxidase activity. After washing in Tris-buffered saline, tissue sections were incubated with monoclonal anti-TS (TS-106; Dako) for $90 \mathrm{~min}$ at room temperature. TS immunohistochemical staining was detected using the Dako REAL EnVision Detection System. After 

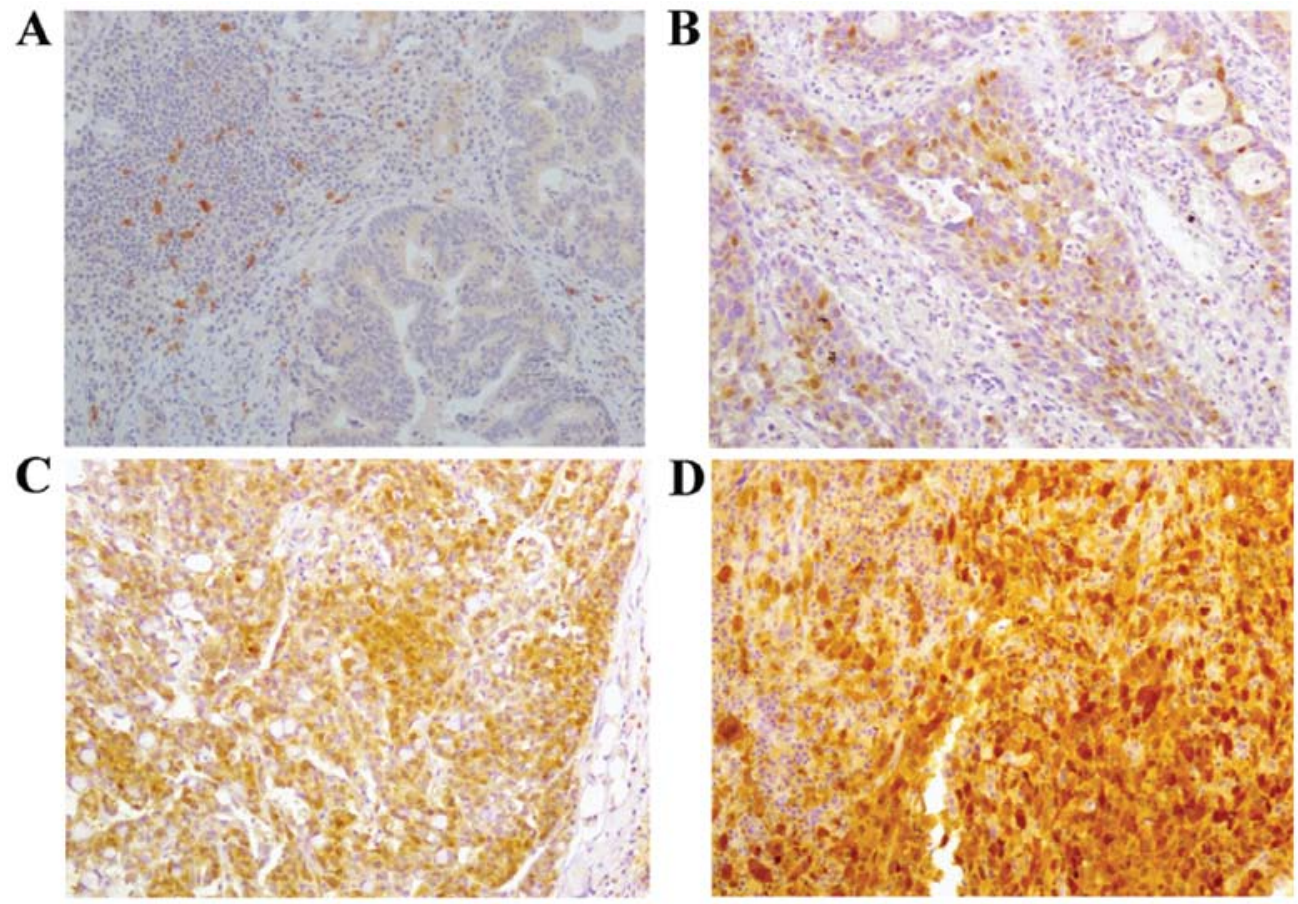

Figure 1. Representative examples of immunohistochemical staining for thymidylate synthase (TS) (magnification, $x 400$ ). Immunohistochemistry results were graded by the cytoplasmic staining intensity as follows: (A) no staining, (B) $1+$, (C) $2+$ and (D) $3+$. The grade of $2+$ or above was regarded as positive expression for TS.

washing, the sections were incubated with the Envision kit for $30 \mathrm{~min}$ at room temperature and 3,3'-diaminobenzidine was applied as the chromogen. After washing, the tissue sections were counterstained with Mayer's hematoxylin. To ensure consistent staining, a positive control (an adenocarcinoma sample with well-characterized staining) and negative control (no primary antibody) were included in each staining run. Adjacent lymphocytes within each section were identified as internal references. Immunohistochemical staining was evaluated by a single pathologist blinded to the clinical parameters. The intensity of TS cytoplasmic staining was graded on a 4 -point scale $(0,1+, 2+$ and $3+)$, and a grade of $\geq 2+$ was considered as positive (Fig. 1).

\section{TS TR polymorphism and $G>C$ SNP analysis}

DNA extraction. Genomic DNA was prepared from FFPE tissue samples using the QIAamp DNA FFPE Tissue kit (Qiagen, Hilden, Germany) according to the manufacturer's protocol. Briefly, the specimen was cut to $20-\mu \mathrm{m}$ tissue sections using a microcutter, and three subsequent sections were transferred to microcentrifuge tubes. Then, PBS was added to each $20-\mu \mathrm{m}$ tissue section and heated for $10 \mathrm{~min}$ at $75^{\circ} \mathrm{C}$. After centrifuging at $13,000 \mathrm{rpm}$, the supernatant was carefully discarded and fresh PBS was added. Tissue samples were then incubated with lysis buffer and proteinase $\mathrm{K}$ for $30 \mathrm{~min}$ at $56^{\circ} \mathrm{C}$. Subsequently, the mixture was applied to the spin column and centrifuged into a collection tube according to the manufacturer's protocol. The purified DNA was used for subsequent analyses.

TS genotyping. TS TR polymorphism and G $>$ C SNP were identified by capillary electrophoresis and direct sequencing of genomic DNA, respectively. For the TS TR assay, DNA was amplified by polymerase chain reaction (PCR) using the HotStarTaq Master Mix kit (Qiagen) with the primer pair 5'-FAM-GTGGCTCCTGCGTTTCCCCC-3' (forward) and 5'-GAGCCGGCCACAGGCATG-3' (reverse). Reactions were set up in a final volume of $25 \mu \mathrm{l}$ with $50 \mathrm{ng}$ of DNA and primers and performed in the 2720 Thermal Cycler (Applied Biosystems, Foster City, CA, USA). The PCR conditions were as follows: initial denaturation at $94^{\circ} \mathrm{C}$ for $15 \mathrm{~min}$, followed by 35 cycles of denaturation at $95^{\circ} \mathrm{C}$ for $30 \mathrm{sec}$, primer annealing at $60^{\circ} \mathrm{C}$ for $30 \mathrm{sec}$, and extension at $72^{\circ} \mathrm{C}$ for $1 \mathrm{~min}$ and final extension at $72^{\circ} \mathrm{C}$ for $5 \mathrm{~min}$. The PCR product $(1 \mu \mathrm{l})$ was added to a mixture of diformamide and GeneScan -500 LIZ Size Standard (Applied Biosystems), denatured at $95^{\circ} \mathrm{C}$ for $2 \mathrm{~min}$, and analyzed using the ABI 3130xl Genetic Analyzer (Applied Biosystems). A peak at 210 base (2R/2R), 238 base (3R/3R), or both of these peaks $(2 R / 3 R)$ were obtained depending on the TS TR status.

Next, to reveal the TS SNP status in the samples containing 3R in the TS TR assay, direct sequencing was performed. PCR for genomic DNA amplification was performed as described for the TS TR assay using the following primer pair: 5'-GT GGCTCCTGCGTTTCCCCC-3' (forward) and 5'-GCTCCG AGCCGGCCACAGGCATGGCGCGG-3' (reverse). Purified PCR products were obtained using an Exonuclease I and Shrimp Alkaline Phosphatase mixture (Fermentas, Vilnius, Lithuania) and subsequently sequenced using the ABI PRISM BigDye Terminator version 3.1 kit (Applied Biosystems). Forward and reverse sequences were analyzed separately under the same conditions with the same primers used in the PCR reaction. Cycle sequencing was performed for 25 cycles of $96^{\circ} \mathrm{C}$ for $30 \mathrm{sec}, 50^{\circ} \mathrm{C}$ for $15 \mathrm{sec}$, and $60^{\circ} \mathrm{C}$ for $4 \mathrm{~min}$. Sequencing analysis was performed using the ABI $3130 \mathrm{XL}$ Genetic Analyzer (Applied Biosystems). 
Table I. Patient and tumor characteristics according to TS SNP status.

\begin{tabular}{|c|c|c|c|c|}
\hline & \multirow[b]{2}{*}{ Total $(n=58)$} & \multicolumn{3}{|c|}{$\mathrm{N}=30^{\mathrm{a}}$} \\
\hline & & $\begin{array}{l}\text { Low TS expression } \\
\text { genotypes }(n=8)\end{array}$ & $\begin{array}{l}\text { High TS expression } \\
\text { genotypes }(n=22)\end{array}$ & P-value \\
\hline \multicolumn{5}{|l|}{ Gender } \\
\hline Male & $39(67)$ & $5(62.5)$ & $12(54.5)$ & \multirow[t]{2}{*}{1.0} \\
\hline Female & $19(33)$ & $3(37.5)$ & $10(45.5)$ & \\
\hline \multicolumn{5}{|l|}{ Age, years } \\
\hline Median & 61 & 62 & 63.5 & \multirow[t]{2}{*}{0.906} \\
\hline Range & $32-83$ & $55-72$ & $32-76$ & \\
\hline \multicolumn{5}{|l|}{ F/U duration (months) } \\
\hline Median & 48.8 & 38.2 & 48.5 & \multirow[t]{2}{*}{0.888} \\
\hline Range & $3.3-121.9$ & $16.8-113.3$ & $3.3-121.9$ & \\
\hline \multicolumn{5}{|l|}{ ECOG performance status } \\
\hline $0-1$ & $42(72)$ & $7(87.5)$ & $16(72.7)$ & \multirow[t]{2}{*}{0.638} \\
\hline $2-3$ & $16(28)$ & $1(12.5)$ & $6(27.3)$ & \\
\hline \multicolumn{5}{|l|}{ Disease status } \\
\hline Metastatic & $43(74)$ & $7(87.5)$ & $16(72.7)$ & \multirow[t]{2}{*}{0.638} \\
\hline Locally advanced & $15(26)$ & $1(12.5)$ & $6(27.3)$ & \\
\hline \multicolumn{5}{|l|}{ Tumor location } \\
\hline Duodenum & $50(86)$ & $8(100)$ & $18(81.8)$ & \multirow[t]{2}{*}{0.550} \\
\hline Jejunum/ileum & $8(14)$ & $0(0)$ & $4(18.2)$ & \\
\hline \multicolumn{5}{|l|}{ Pathologic differentiation } \\
\hline Well & $9(16)$ & $3(37.5)$ & $4(18.2)$ & \multirow[t]{4}{*}{0.352} \\
\hline Moderate & $23(40)$ & $2(25.0)$ & $7(31.8)$ & \\
\hline Poor & $16(28)$ & $1(12.5)$ & $9(40.9)$ & \\
\hline Unknown & $10(17)$ & $1(12.5)$ & $2(9.1)$ & \\
\hline \multicolumn{5}{|l|}{ Pretreatment CEA level (ng/ml) } \\
\hline Median & 2.2 & 1.8 & 2.5 & \multirow[t]{2}{*}{0.489} \\
\hline Range & $0.5-100.0$ & $1.2-14.8$ & $0.5-100.0$ & \\
\hline \multicolumn{5}{|l|}{ Prior fluoropyrimidine use } \\
\hline No & $46(79)$ & $7(87.5)$ & $17(77.3)$ & \multirow[t]{2}{*}{1.0} \\
\hline Yes & $12(21)$ & $1(12.5)$ & $5(22.7)$ & \\
\hline \multicolumn{5}{|l|}{ First-line chemotherapy } \\
\hline Cisplatin + fluoropyrimidine & $31(53)$ & $6(75.0)$ & $14(63.6)$ & \multirow[t]{4}{*}{0.837} \\
\hline Oxaliplatin + fluoropyrimidine & $11(19)$ & $1(12.5)$ & $5(22.7)$ & \\
\hline Irinotecan + fluoropyrimidine & $6(10)$ & $0(0)$ & $1(4.5)$ & \\
\hline Fluoropyrimidine alone & $10(17)$ & $1(12.5)$ & $2(9.1)$ & \\
\hline \multicolumn{5}{|l|}{ No. of chemotherapy cycles } \\
\hline Median & 4 & 9 & 3.5 & \multirow[t]{2}{*}{0.003} \\
\hline Range & $1-50$ & $3-50$ & $1-10$ & \\
\hline
\end{tabular}

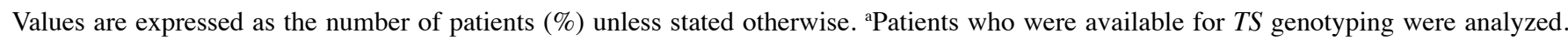
Based on TS TR and SNP status, patients were classified into low TS expression genotypes (2R/2R, 2R/3RC, and 3RC/3RC) and high TS expression genotypes (2R/3RG, 3RC/3RG, and 3RG/3RG). TS, thymidylate synthase; SNP, single-nucleotide polymorphism; F/U, follow-up; ECOG, Eastern Cooperative Oncology Group; CEA, carcinoembryonic antigen.

Based on the TS TR and SNP status, TS genotypes were classified as high TS expression genotypes $(2 \mathrm{R} / 3 \mathrm{RG}, 3 \mathrm{RC} / 3 \mathrm{RG}$ and $3 R G / 3 R G)$ or low TS expression genotypes $(2 R / 2 R$, 2R/3RC and 3RC/3RC).
Statistical analysis. PFS and OS were calculated using the Kaplan-Meier method and compared using the log-rank test. Clinical variables, such as age, gender, disease status, Eastern Cooperative Oncology Group (ECOG) performance status, 
Table II. TS protein expression according to TS TR and SNP status.

\begin{tabular}{lcccc}
\hline & \multicolumn{3}{c}{$T S$ TR status } & P-value \\
\cline { 2 - 4 } TS protein expression & 2R/2R, 2R/3R & $3 R / 3 R$ & Total & 0.127 \\
\hline Negative & $9(69)$ & $7(41)$ & $16(9)$ & $14(10)$ \\
Positive & $4(31)$ & $10(59)$ & & \\
\hline
\end{tabular}

TS SNP status

\begin{tabular}{|c|c|c|c|c|c|c|c|c|c|}
\hline \multirow[b]{2}{*}{ TS protein expression ${ }^{a}$} & \multicolumn{4}{|c|}{ Low-expression genotypes } & \multicolumn{4}{|c|}{ High-expression genotypes } & \multirow[b]{2}{*}{ P-value } \\
\hline & $2 \mathrm{R} / 2 \mathrm{R}$ & $2 \mathrm{R} / 3 \mathrm{RC}$ & $3 \mathrm{RC} / 3 \mathrm{RC}$ & Total & $2 \mathrm{R} / 3 \mathrm{RG}$ & $3 \mathrm{RC} / 3 \mathrm{RG}$ & $3 R G / 3 R G$ & Total & \\
\hline Nega & $2(67)$ & $2(100)$ & $3(100)$ & $7(88)$ & $5(63)$ & $2(33)$ & $2(25)$ & $9(41)$ & 0.039 \\
\hline Positive & $1(33)$ & $0(0)$ & $0(0)$ & $1(13)$ & $3(38)$ & $4(67)$ & $6(75)$ & $13(59)$ & \\
\hline
\end{tabular}

Values are expressed as the number of patients (\%). ${ }^{a} \mathrm{TS}$ protein expression was evaluated by the intensity of TS immunohistochemical staining TS, thymidylate synthase; SNP, single-nucleotide polymorphism; TR, tandem repeat.

location of the primary tumor, histologic grade, pretreatment CEA and systemic chemotherapy were included for analysis. Descriptive statistics were summarized as frequencies and percentages for categorical variables and as median and range for continuous variables. Comparison of clinical variables according to TS genotypes and comparisons between TS immunohistochemical staining intensity and TS polymorphisms (TR, SNP) and tumor response were made using $\chi^{2}$ test or Fisher's exact test. Multivariate analysis was carried out using the Cox proportional hazards models. Variables with $\mathrm{P}<0.05$ in the univariate analysis were included in the multivariate model using a forward conditional method, and hazard ratio (HR) and $95 \%$ confidence interval (CI) were calculated. A two-tailed P-value of $<0.05$ was considered statistically significant. All data analyses were carried out using SPSS software (SPSS, Inc., Chicago, IL, USA).

\section{Results}

Patient cohort. We identified 64 patients at 10 Korean institutions who were diagnosed with locally advanced/metastatic SBA and treated with first-line fluoropyrimidine-based regimens between 2003 and 2012. Of the 64 patients, four patients were not included because they were initially treated with fluoropyrimidines as a radiosensitizer during concurrent chemoradiotherapy. Two patients were excluded, because they did not complete their first cycle of capecitabine monotherapy owing to non-hematologic toxicity. Thus, 58 patients were included in this analysis.

Patient characteristics. The demographic and clinical characteristics of the patients are listed in Table I. Of the 58 patients, $39(67 \%)$ were male and $19(33 \%)$ were female, with a median age of 61 years (range, $32-83$ years). The most common primary tumor location was the duodenum $(50 / 58$, $86 \%$ ). Metastatic disease was present in 43 patients (74\%), and the ECOG performance status was 0 or 1 in 42 patients $(72 \%)$. The median CEA level was $2.2 \mathrm{ng} / \mathrm{ml}$ (range, $0.5-100.0 \mathrm{ng} / \mathrm{ml}$ ).
Twelve patients $(21 \%)$ had a history of prior fluoropyrimidine adjuvant therapy. Thirty-one patients $(53 \%)$ received the FP regimen, 11 patients (19\%) received the FOLFOX regimen, 10 patients $(17 \%)$ received fluoropyrimidine alone, and 6 patients (10\%) received the FOLFIRI regimen as first-line chemotherapy.

Association between immunohistochemical expression of TS and TS genotype. TS IHC and genotyping were successfully performed in 30 cases (52\%); the remaining 28 cases lacked sufficient tissue samples for analysis. TS immunohistochemical staining exhibited a predominantly diffuse pattern throughout the nucleus and cytoplasm of the tumor cells. TS immunohistochemical staining intensity was follows: 0 in 8 cases $(27 \%)$, $1+$ in 8 cases $(27 \%), 2+$ in 11 cases $(37 \%)$, and $3+$ in $3(8 \%)$. Among these cases, 14 (47\%) were considered positive for TS expression $(\geq 2+)$. The $T S$ TR status was $2 \mathrm{R} / 2 \mathrm{R}$ in 3 patients (10\%), $2 \mathrm{R} / 3 \mathrm{R}$ in 10 patients $(33 \%)$, and $3 \mathrm{R} / 3 \mathrm{R}$ in 17 patients (57\%). The SNP status was $2 \mathrm{R} / 3 \mathrm{RC}$ in 2 patients $(7 \%), 2 \mathrm{R} / 3 \mathrm{RG}$ in 8 patients (27\%), 3RC/3RC in 3 patients $(10 \%), 3 \mathrm{RC} / 3 \mathrm{RG}$ in 6 patients (20\%), and 3RG/3RG in 8 patients $(27 \%)$. Based on the TS SNP status in the TR sequence, 22 patients $(73 \%)$ had high TS expression genotypes (2R/3RG, 3RC/3RG, 3RG/3RG) and the remaining 8 patients had low TS expression genotypes (2R/2R, 2R/3RC, 3RC/3RC; Table II).

The prevalence of positive TS immunohistochemical expression was not significantly different between patients with the $3 R / 3 R$ genotype and those with the $2 R / 2 R$ and $2 R / 3 R$ genotypes [59\% (10/17) vs. $31 \%$ (4/13); $\mathrm{P}=0.127$; Table II]. In contrast, the prevalence of positive TS immunohistochemical expression was significantly higher in patients with high TS expression genotypes than in those with low TS expression genotypes (59 vs. 13\%; $\mathrm{P}=0.039$; Table II).

Correlations of TS protein expression and genotype with treatment response, PFS and $O S$. Tumor response was evaluable in $29(97 \%)$ of the 30 patients in whom TS immunohistochemical expression and genotype data were available. One patient did 
Table III. Treatment response according to TS protein expression and TS TR and SNP status.

\begin{tabular}{|c|c|c|c|c|c|c|c|c|c|c|}
\hline \multirow[b]{2}{*}{$\begin{array}{l}\text { Treatment } \\
\text { response }\end{array}$} & \multirow[b]{2}{*}{ Total } & \multicolumn{3}{|c|}{ TS protein expression } & \multicolumn{3}{|c|}{$T S$ TR status } & \multicolumn{3}{|c|}{ TS SNP status } \\
\hline & & Negative & Positive & P-value & $2 \mathrm{R} / 2 \mathrm{R}, 2 \mathrm{R} / 3 \mathrm{R}$ & $3 R / 3 R$ & P-value & $\begin{array}{c}\text { Low-expression } \\
\text { genotypes }\end{array}$ & $\begin{array}{l}\text { High-expression } \\
\text { genotypes }\end{array}$ & P-value \\
\hline $\mathrm{CR} / \mathrm{PR}$ & $10(35)$ & $7(47)$ & $3(21)$ & 0.245 & $5(42)$ & $5(29)$ & 0.694 & $5(71)$ & $5(23)$ & 0.030 \\
\hline $\mathrm{SD} / \mathrm{PD}$ & $19(66)$ & $8(53)$ & $11(79)$ & & $7(58)$ & $12(71)$ & & $2(79)$ & $17(77)$ & \\
\hline
\end{tabular}

Values are expressed as the number of patients (\%). TS, thymidylate synthase; TR, tandem repeat; SNP, single-nucleotide polymorphism; CR, complete response; $\mathrm{PR}$, partial response; $\mathrm{SD}$, stable disease; $\mathrm{PD}$, progressive disease.
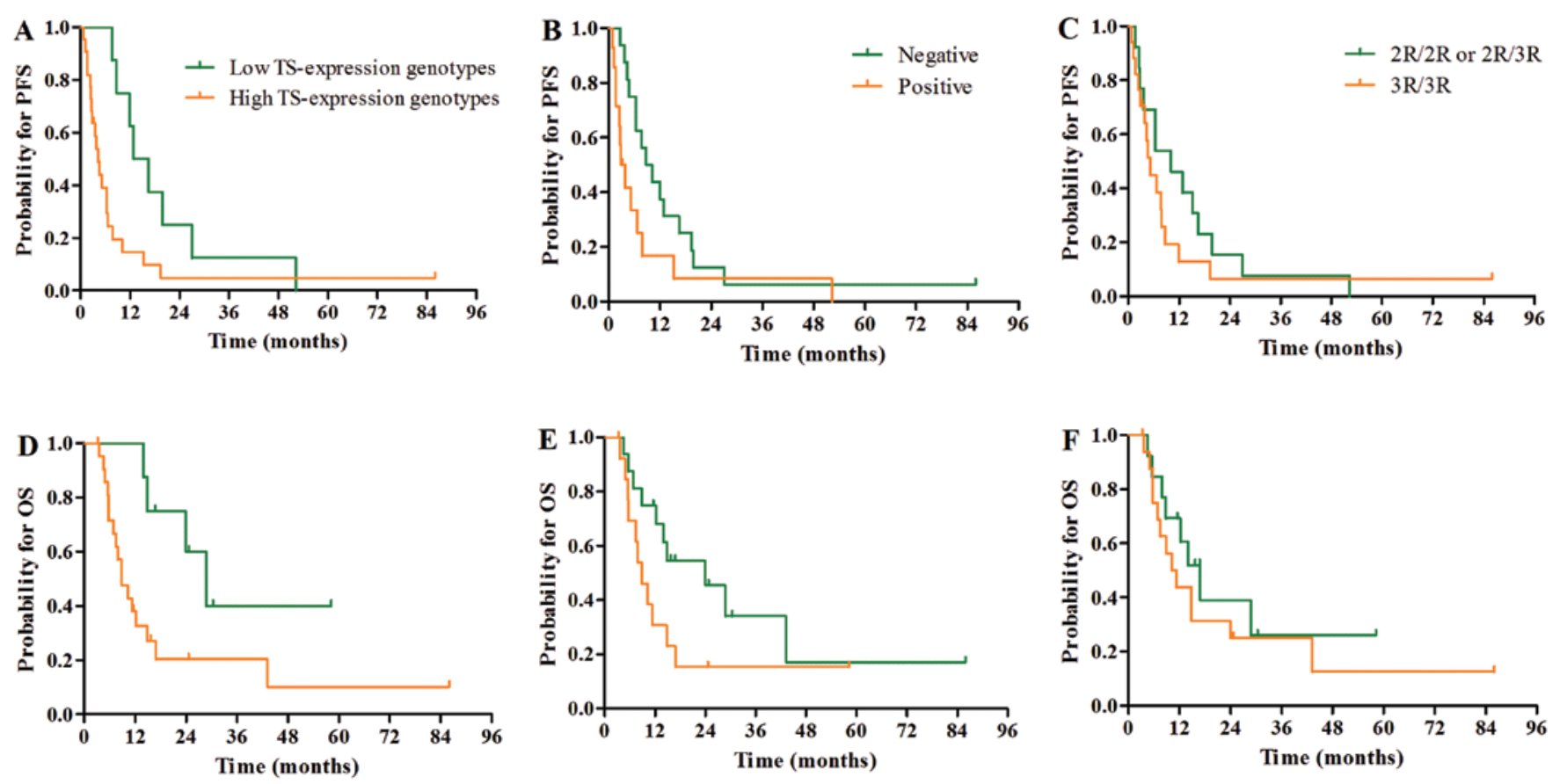

Figure 2. Comparison of progression-free survival (PFS, upper) and overall survival (OS, lower) according to the thymidylate synthase (TS) genotypes based on G $>C$ single-nucleotide polymorphism (SNP) within the tandem repeat (TR) sequence, TS immunohistochemistry, and TS TR polymorphism. (A) PFS and (D) OS were significantly longer in patients with low TS expression genotypes than in those with high TS expression genotypes. A non-significant trend towards a better (B) PFS and (E) OS was observed in patients with negative TS protein expression. TS TR polymorphism status did not significantly affect (C) PFS or (F) OS.

not have any evaluable lesions at baseline. Among the evaluable patients, 10 patients (1 complete response and 9 partial response) responded to treatments, resulting in an overall response rate (ORR) of $35 \%$. The ORR was not significantly different according to TS protein expression and TR polymorphism status (Table III). However, the ORR was significantly higher in patients with low TS expression genotypes than in those with high TS expression genotypes (71 vs. 23\%; $\mathrm{P}=0.030$; Table III).

With a median follow-up duration of 48.8 months (range, 3.3-121.9 months), median PFS and OS were 6.0 months (95\% CI, 4.5-7.5) and 11.3 months (95\% CI, 8.1-14.5), respectively. Median PFS and OS were 12.8 months (95\% CI, 6.4-19.2) and 28.8 months (95\% CI, 19.2-38.4) in patients with low TS expression genotypes and 4.3 months (95\% CI, 2.9-5.7) and 8.9 months (95\% CI, 5.5-12.3) in patients with high TS expression genotypes, respectively. Patients with low TS expression genotypes had significantly better PFS and OS than those with high TS expression genotypes ( $\mathrm{PFS}, \mathrm{P}=0.027$; OS, $\mathrm{P}=0.025$; Fig. 2A and D).

Although there was a trend towards a better PFS (median, 8.7 vs. 2.8 months; $\mathrm{P}=0.060$ ) and $\mathrm{OS}$ (median, 24.0 vs. 8.9 months; $\mathrm{P}=0.090$ ) in favor of the negative TS protein expression group, PFS and OS were not significantly different according to TS protein expression (Fig. 2B and E) and TS TR polymorphism status (Fig. $2 \mathrm{C}$ and $\mathrm{F}$ ).

The results of the univariate and multivariate analyses for PFS and OS are shown in Tables IV and V. In univariate analysis, ECOG performance status $(\mathrm{P}<0.001)$ and TS SNP status $(\mathrm{P}=0.025)$ were significantly associated with OS (Table IV). In the multivariate analysis, poor ECOG performance status (HR, 2.85; 95\% CI, 1.02-7.93) and high TS expression genotypes (HR, 3.49; 95\% CI, 1.13-10.78) were independent prognostic factors for worse OS (Table V). 
Table IV. Univariate analysis for PFS and OS.

\begin{tabular}{|c|c|c|c|c|c|}
\hline Variables & No. of patients & $\begin{array}{l}\text { Median PFS } \\
(\mathrm{ms}, 95 \% \mathrm{CI})\end{array}$ & P-value & $\begin{array}{c}\text { Median OS } \\
(\mathrm{ms}, 95 \% \mathrm{CI})\end{array}$ & P-value \\
\hline \multicolumn{6}{|l|}{ Age at diagnosis (years) } \\
\hline$\leq 60$ & 27 & $6.4(4.1-8.7)$ & \multirow[t]{2}{*}{0.910} & $14.8(11.1-18.5)$ & \multirow[t]{2}{*}{0.995} \\
\hline$>60$ & 31 & $5.2(3.0-7.4)$ & & $10.2(7.7-12.7)$ & \\
\hline \multicolumn{6}{|l|}{ Gender } \\
\hline Male & 39 & $6.0(4.2-7.8)$ & \multirow[t]{2}{*}{0.977} & $12.2(8.4-16.0)$ & \multirow[t]{2}{*}{0.630} \\
\hline Female & 19 & $6.4(2.6-10.2)$ & & $14.0(6.1-21.9)$ & \\
\hline \multicolumn{6}{|l|}{ ECOG performance status } \\
\hline $0-1$ & 42 & $7.3(5.8-8.8)$ & \multirow[t]{2}{*}{$<0.001$} & $14.8(11.6-18.0)$ & \multirow[t]{2}{*}{$<0.001$} \\
\hline $2-3$ & 16 & $2.7(2.1-3.3)$ & & $5.0(3.4-6.6)$ & \\
\hline \multicolumn{6}{|l|}{ Disease status } \\
\hline Locally advanced & 15 & $8.7(0.1-17.3)$ & \multirow[t]{2}{*}{0.064} & $19.2(5.5-32.9)$ & \multirow[t]{2}{*}{0.265} \\
\hline Metastatic & 43 & $5.5(3.4-7.6)$ & & $10.6(9.0-12.2)$ & \\
\hline \multicolumn{6}{|l|}{ Tumor location } \\
\hline Duodenum & 50 & $6.3(4.8-7.8)$ & \multirow[t]{2}{*}{0.277} & $11.3(7.2-15.4)$ & \multirow[t]{2}{*}{0.863} \\
\hline Jejunum/ileum & 8 & $3.8(3.3-4.3)$ & & $12.2(8.9-15.5)$ & \\
\hline \multicolumn{6}{|l|}{ Pathologic differentiation } \\
\hline Well & 9 & $11.9(4.7-19.1)$ & \multirow[t]{3}{*}{0.104} & $24.0(0.2-47.8)$ & \multirow[t]{3}{*}{0.284} \\
\hline Moderate & 23 & $3.9(2.0-5.8)$ & & $11.1(6.7-15.5)$ & \\
\hline Poor & 16 & $4.3(1.7-6.9)$ & & $10.6(8.4-12.7)$ & \\
\hline \multicolumn{6}{|l|}{ Pretreatment CEA level (ng/ml) } \\
\hline$\leq 2.2$ & 23 & $3.8(3.4-4.2)$ & \multirow[t]{2}{*}{0.364} & $11.1(5.8-16.4)$ & \multirow[t]{2}{*}{0.860} \\
\hline$>2.2$ & 22 & $6.3(4.8-7.8)$ & & $8.9(4.1-13.7)$ & \\
\hline \multicolumn{6}{|l|}{ Chemotherapy } \\
\hline Cisplatin + fluoropyrimidine & 31 & $6.7(5.3-8.1)$ & \multirow[t]{4}{*}{0.128} & $14.0(9.3-18.7)$ & \multirow[t]{4}{*}{0.083} \\
\hline Oxaliplatin + fluoropyrimidine & 11 & $3.9(2.2-5.6)$ & & $11.3(2.6-20.0)$ & \\
\hline Irinotecan + fluoropyrimidine & 6 & $3.7(2.0-5.4)$ & & $4.7(0-9.6)$ & \\
\hline Fluoropyrimidine alone & 10 & $5.5(0-25.1)$ & & $30.5(0-75.6)$ & \\
\hline \multicolumn{6}{|l|}{ Prior fluoropyrimidine use } \\
\hline No & 46 & $5.8(3.9-7.7)$ & \multirow[t]{2}{*}{0.642} & $10.6(6.5-14.7)$ & 0.952 \\
\hline Yes & 12 & $6.3(1.5-11.1)$ & & $13.6(9.5-17.7)$ & \\
\hline TS protein expression & & & & & \\
\hline Negative & 16 & $8.7(4.0-13.4)$ & 0.060 & $24.0(9.6-38.4)$ & 0.090 \\
\hline Positive & 14 & $2.8(0.9-4.7)$ & & $8.9(5.7-12.1)$ & \\
\hline$T S$ TR status & & & & & \\
\hline $2 \mathrm{R} / 2 \mathrm{R}, 2 \mathrm{R} / 3 \mathrm{R}$ & 13 & $10.1(2.0-18.2)$ & 0.336 & $16.9(10.3-23.5)$ & 0.397 \\
\hline $3 R / 3 R$ & 17 & $5.2(3.5-6.9)$ & & $10.2(5.5-14.9)$ & \\
\hline TS SNP status & & & & & \\
\hline Low expression genotypes & 8 & $12.8(6.4-19.2)$ & 0.027 & $28.8(19.2-38.4)$ & 0.025 \\
\hline High expression genotypes & 22 & $4.3(2.9-5.7)$ & & $8.9(5.5-12.3)$ & \\
\hline
\end{tabular}

PFS, progression-free survival; OS, overall survival; CI, confidence interval; ms, months; ECOG, Eastern Cooperative Oncology Group; CEA, carcinoembryonic antigen; TS, thymidylate synthase; TR, tandem repeat; SNP, single-nucleotide polymorphism.

\section{Discussion}

Thymidylate synthase (TS) is a target of fluoropyrimidines, and TS expression has been demonstrated to be a determinant of fluoropyrimidine sensitivity in vitro $(11,12)$. Subsequent clin- ical studies have also suggested that the TS level is associated with fluoropyrimidine sensitivity (13-15). Fluoropyrimidines have been essential backbone drugs for the treatment of gastrointestinal malignancies, including SBA (24). Since SBA is a rare malignancy, it may be meaningful to identify biologic 
Table V. Multivariate analysis for PFS and OS.

\begin{tabular}{lccc}
\hline Variables & HR & $95 \%$ CI & P-value \\
\hline PFS & & & \\
$\quad$ ECOG performance status & & & \\
$\quad 0-1$ & 1 & & 0.034 \\
$2-3$ & 2.70 & $1.08-6.75$ & \\
TS SNP status & & & \\
$\quad$ Low expression genotypes & 1 & & \\
$\quad$ High expression genotypes & 2.47 & $1.05-5.79$ & 0.038 \\
OS & & & \\
ECOG performance status & & & \\
$\quad 0-1$ & 1 & & \\
2-3 & 2.85 & $1.02-7.93$ & 0.046 \\
TS SNP status & & & \\
$\quad$ Low expression genotypes & 1 & & 0.030 \\
High expression genotypes & 3.49 & $1.13-10.78$ & \\
\hline
\end{tabular}

PFS, progression-free survival; OS, overall survival; HR, hazard ratio; CI, confidence interval; ECOG, Eastern Cooperative Oncology Group; TS, thymidylate synthase; SNP, single-nucleotide polymorphism.

prognostic factors for current therapy. However, to date, data regarding the prognostic role of TS in patients with SBA receiving fluoropyrimidine-based chemotherapy are lacking. Therefore, we investigated the impact of immunohistochemical expression of TS protein and TS 5'-UTR polymorphisms on treatment outcomes of fluoropyrimidine-based chemotherapy in patients with advanced SBA. To the best of our knowledge, this is the first study to investigate the role of drug sensitivity in regards to TS protein expression and TS polymorphisms (SNP and TR) in patients with advanced SBA.

In the present study, we demonstrated that the TS genotype, identified by the G>C SNP status in the TS TR sequence, may correlate with TS protein expression and influence ORR, PFS, and OS in patients with locally advanced/metastatic SBA treated with first-line fluoropyrimidine-based chemotherapy. Notably, the present study also showed that the TS TR polymorphism alone is not a sufficient marker to predict response to fluoropyrimidine-based chemotherapy. These findings are consistent with recent studies demonstrating that TS activity was regulated by the G>C SNP as well as the TR polymorphism in the 5'-UTR of the TS gene (19-21). The number of TR in the $T S$ gene is associated with TS activity. The translational efficiency of $T S$ mRNA is generally three to four times higher with the $3 R$ sequence than with the $2 R$ sequence $(16,17,25)$. Recent clinical studies in patients with metastatic CRC have shown that patients with the $3 \mathrm{R} / 3 \mathrm{R}$ genotype were significantly associated with a poorer response to $5-\mathrm{FU}$ than those containing the $2 \mathrm{R}$ genotype (26,27). However, some studies have found no association between $T S$ TR polymorphism and response to 5-FU-based chemotherapy $(28,29)$. A G $>$ C SNP in the second repeat of the $3 \mathrm{R}$ alleles may partially explain these discrepancies (18). Functional analysis has demonstrated that translational efficiency of the $3 \mathrm{R}$ sequence is three to four times greater without the G>C SNP than with the G>C SNP
$(18,19)$. As a result, the $3 \mathrm{RC}$ alleles may have a similar translational efficiency to that of the $2 \mathrm{R}$ alleles.

Given that fluoropyrimidine-based cytotoxic chemotherapy is currently regarded as the mainstay of treatment in patients with advanced SBA (24), the present study suggests that the TS genotype may serve as a biomarker of response to fluoropyrimidine-based chemotherapy. In this analysis, median OS among patients with low TS expression genotypes was more than 28 months. Thus, the therapeutic approach in these patients should take into account not only an efficacy of chemotherapeutic agents but also toxicity and quality-of-life implications. Therefore, trials involving such patients should incorporate both patient-reported quality-of-life end points and survival parameters to aid therapeutic decision making. On the other hand, the outcomes of patients with high TS expression genotypes were dismal; thus, the development of novel targeted treatment strategies is urgently needed for this group of patients. Although targeted therapies incorporating bevacizumab or cetuximab are commonly used for the treatment of CRC, the role of targeted therapies in advanced SBA has not yet been established. However, studies investigating the molecular pathology of SBA suggest that targeted therapies hold promise in the treatment of this disease. Notably, vascular endothelial growth factor is highly expressed in SBA, and the frequency of KRAS mutations is similar in SBA and CRC (30-32). Furthermore, several case series have reported the promising efficacy of cetuximab in patients with KRAS wild-type SBA $(33,34)$. Therefore, the $T S$ genotype will allow for the identification of patients with a poor prognosis who preferentially require novel targeted treatment other than fluoropyrimidine-based cytotoxic chemotherapy. Prospective studies are urgently needed to validate our results.

Even though data on the $T S$ genotypes in patients with SBA are lacking, previous studies in patients with CRC have suggested the ethnic difference in the distribution of $T S$ genotypes (35). In the present study, 3R/3R was the most prevalent allele with a frequency of $57 \%$, whereas $2 \mathrm{R} / 2 \mathrm{R}$ and 2R/3R occurred at frequencies of 10 and $33 \%$, respectively. Furthermore, the frequency of high TS expression genotypes was much higher than that of low TS expression genotypes (73 vs. 27\%). This result is consistent with previous studies of Korean CRC patients $(22,36)$. However, the proportion of patients with high and low TS expression genotypes was reported to be similar in Caucasian ethnic group $(18,20,35)$. Because of the small sample size, we could not conclusively predict the difference in the distribution of $T S$ genotypes according to ethnicity. Therefore, further studies are required to understand whether this difference may affect the different prognosis following fluoropyrimidine-based chemotherapy between Asian and Caucasian ethnic groups.

The results of the present study suggest that the TS genotype based on both TS SNP and TR status is correlated with the immunohistochemical expression of TS protein. However, the results should be interpreted with caution, since previous studies investigating immunohistochemical expression of TS as a surrogate marker for TS expression have been inconclusive. Until recently, the predictive value of TS expression for response to 5-FU-based chemotherapy was mainly investigated in metastatic CRC $(37,38)$. These studies produced conflicting rather than conclusive results. Recent meta-analyses concluded 
that advanced CRC with high TS expression levels seem to be less sensitive to fluoropyrimidine-based chemotherapy, although evidence of heterogeneity and possible publication bias was observed $(39,40)$. Differences in methodology and TS status assessment criteria might have contributed to the heterogeneity between studies (39). The most commonly used method to determine TS expression is IHC. IHC is a convenient technique with multiple advantages, thus making it a desirable approach for biomarker study. However, significant limitations exist due to the variability in its technical aspects, such as the antibodies used and staining technique. Additionally, differences in the IHC scoring methods used to dichotomize TS expression might contribute to the conflicting results $(39,40)$. Therefore, TS immunohistochemical expression as a surrogate biomarker of TS expression might need further clarification and validation in patients with advanced SBA.

The present study has several limitations. First, the present analysis is based on retrospective data obtained from a small number of patients; therefore, unexpected selection bias may be present. Second, our study focused solely on the prognostic role of the G>C SNP and TR polymorphism of the 5'-UTR of the $T S$ gene in SBA patients treated with fluoropyrimidines-based chemotherapy. However, the effects of other genetic polymorphism of the TS gene (i.e., 6-bp deletion in the 3'-UTR) were not investigated in this analysis. Moreover, an evaluation of the impact of other fluoropyrimidine metabolic enzymes, such as thymidylate phosphorylase, dihydropyrimidine dehydrogenase, and methylenetetrahydrofolate reductase, on treatment outcomes was beyond the scope of this study. Additional studies are necessary to examine the impact of these enzymes on clinical outcomes in patients with advanced SBA. Finally, prospective randomized studies are needed to validate our results. However, the rarity of advanced SBA makes randomized trials virtually difficult. Hence, cooperation between study groups is crucial to conduct such studies. Nevertheless, our study is the first to demonstrate the prognostic relevance of the $T S$ genotype in patients with advanced SBA treated with first-line fluoropyrimidine-based chemotherapy.

In conclusion, the $T S$ genotype based on G>C SNP and TR polymorphism appears to be an independent predictor of PFS and OS in patients with locally advanced/metastatic SBA treated with first-line fluoropyrimidine-based chemotherapy. Our findings represent a promising step toward the optimization of treatment strategies in advanced SBA. Further prospective studies with international collaboration are required to verify the prognostic role of the $T S$ genotype in advanced SBA.

\section{Acknowledgements}

We would especially like to thank Dr Dong Sug Kim for his excellent assistance in the TS IHC. The present study was supported by funding from the Biomedical Research Institute, Chonbuk National University Hospital and also supported by a grant from the National R\&D Program for Cancer Control, Ministry of Health \& Welfare, Republic of Korea (0620220-1).

\section{References}

1. Neugut AI, Jacobson JS, Suh S, Mukherjee R and Arber N: The epidemiology of cancer of the small bowel. Cancer Epidemiol Biomarkers Prev 7: 243-251, 1998.
2. Xiang XJ, Liu YW, Zhang L, Qiu F, Yu F, Zhan ZY, Feng M Yan J, Zhao JG and Xiong JP: A phase II study of modified FOLFOX as first-line chemotherapy in advanced small bowel adenocarcinoma. Anticancer Drugs 23: 561-566, 2012.

3. Overman MJ, Varadhachary GR, Kopetz S, Adinin R, Lin E, Morris JS, Eng C, Abbruzzese JL and Wolff RA: Phase II study of capecitabine and oxaliplatin for advanced adenocarcinoma of the small bowel and ampulla of Vater. J Clin Oncol 27: 2598-2603, 2009.

4. McWilliams RR, Mahoney MR, Marchello BT, Jatoi A, Krewer KD, Ames MA, Schneider DJ, Seeger GR, Mowat RB, Alberts SR and Goetz MP: Pharmacogenetic dosing by UGT1A1 genotype as first-line therapy for advanced small-bowel adenocarcinoma: A North Central Cancer Treatment Group (NCCTG) trial. Clin Oncol 30 (Suppl 4): 314, 2012.

5. Gibson MK, Holcroft CA, Kvols LK and Haller D: Phase II study of 5-fluorouracil, doxorubicin, and mitomycin $\mathrm{C}$ for metastatic small bowel adenocarcinoma. Oncologist 10: 132-137, 2005.

6. Zaanan A, Costes L, Gauthier M, Malka D, Locher C, Mitry E, Tougeron D, Lecomte T, Gornet JM, Sobhani I, et al: Chemotherapy of advanced small-bowel adenocarcinoma: A multicenter AGEO study. Ann Oncol 21: 1786-1793, 2010.

7. Tsushima T, Taguri M, Honma Y, Takahashi H, Ueda S, Nishina T, Kawai H, Kato S, Suenaga M, Tamura F, et al: Multicenter retrospective study of 132 patients with unresectable small bowel adenocarcinoma treated with chemotherapy. Oncologist 17: 1163-1170, 2012.

8. Fishman PN, Pond GR, Moore MJ, Oza A, Burkes RL, Siu LL, Feld R, Gallinger S, Greig P and Knox JJ: Natural history and chemotherapy effectiveness for advanced adenocarcinoma of the small bowel: A retrospective review of 113 cases. Am J Clin Oncol 29: 225-231, 2006.

9. Santi DV, McHenry CS and Sommer H: Mechanism of interaction of thymidylate synthetase with 5-fluorodeoxyuridylate. Biochemistry 13: 471-481, 1974.

10. Danenberg PV, Heidelberger C, Mulkins MA and Peterson AR: The incorporation of 5-fluoro-2'-deoxyuridine into DNA of mammalian tumor cells. Biochem Biophys Res Commun 102: 654-658, 1981

11. Johnston PG, Drake JC, Trepel J and Allegra CJ: Immunological quantitation of thymidylate synthase using the monoclonal antibody TS 106 in 5-fluorouracil-sensitive and -resistant human cancer cell lines. Cancer Res 52: 4306-4312, 1992.

12. van Triest B, Pinedo HM, van Hensbergen Y, Smid K, Telleman F, Schoenmakers PS, van der Wilt CL, van Laar JA, Noordhuis P, Jansen G, et al: Thymidylate synthase level as the main predictive parameter for sensitivity to 5-fluorouracil, but not for folate-based thymidylate synthase inhibitors, in 13 nonselected colon cancer cell lines. Clin Cancer Res 5: 643-654, 1999.

13. Leichman L, Lenz HJ, Leichman CG, Groshen S, Danenberg K, Baranda J, Spears CP, Boswell W, Silberman H, Ortega A, et al: Quantitation of intratumoral thymidylate synthase expression predicts for resistance to protracted infusion of 5-fluorouracil and weekly leucovorin in disseminated colorectal cancers: Preliminary report from an ongoing trial. Eur J Cancer 31A: 1306-1310, 1995.

14. Leichman CG, Lenz HJ, Leichman L, Danenberg K, Baranda J, Groshen S, Boswell W, Metzger R, Tan M and Danenberg PV: Quantitation of intratumoral thymidylate synthase expression predicts for disseminated colorectal cancer response and resistance to protracted-infusion fluorouracil and weekly leucovorin. J Clin Oncol 15: 3223-3229, 1997.

15. Liersch T, Langer C, Ghadimi BM, Kulle B, Aust DE, Baretton GB, Schwabe W, Häusler P, Becker H and Jakob C: Lymph node status and TS gene expression are prognostic markers in stage II/III rectal cancer after neoadjuvant fluorouracil-based chemoradiotherapy. J Clin Oncol 24: 4062-4068, 2006.

16. Horie N, Aiba H, Oguro K, Hojo H and Takeishi K: Functional analysis and DNA polymorphism of the tandemly repeated sequences in the 5'-terminal regulatory region of the human gene for thymidylate synthase. Cell Struct Funct 20: 191-197, 1995.

17. Kawakami K, Omura K, Kanehira E and Watanabe Y: Polymorphic tandem repeats in the thymidylate synthase gene is associated with its protein expression in human gastrointestinal cancers. Anticancer Res 19: 3249-3252, 1999.

18. Mandola MV, Stoehlmacher J, Muller-Weeks S, Cesarone G, Yu MC, Lenz HJ and Ladner RD: A novel single nucleotide polymorphism within the $5^{\prime}$ tandem repeat polymorphism of the thymidylate synthase gene abolishes USF-1 binding and alters transcriptional activity. Cancer Res 63: 2898-2904, 2003. 
19. Kawakami $\mathrm{K}$ and Watanabe $\mathrm{G}$ : Identification and functional analysis of single nucleotide polymorphism in the tandem repeat sequence of thymidylate synthase gene. Cancer Res 63: 6004-6007, 2003.

20. Marcuello E, Altés A, del Rio E, César A, Menoyo A and Baiget M: Single nucleotide polymorphism in the 5 ' tandem repeat sequences of thymidylate synthase gene predicts for response to fluorouracil-based chemotherapy in advanced colorectal cancer patients. Int J Cancer 112: 733-737, 2004.

21. Fernández-Contreras ME, Sánchez-Prudencio S, SánchezHernández JJ, García de Paredes ML, Gisbert JP, Roda-Navarro P and Gamallo C: Thymidylate synthase expression pattern, expression level and single nucleotide polymorphism are predictors for disease-free survival in patients of colorectal cancer treated with 5-fluorouracil. Int J Oncol 28: 1303-1310, 2006.

22. Hur H, Kang J, Kim NK, Min BS, Lee KY, Shin SJ, Keum KC, Choi J, Kim H, Choi SH, et al: Thymidylate synthase gene polymorphism affects the response to preoperative 5-fluorouracil chemoradiation therapy in patients with rectal cancer. Int J Radiat Oncol Biol Phys 81: 669-676, 2011.

23. Therasse P, Arbuck SG, Eisenhauer EA, Wanders J, Kaplan RS, Rubinstein L, Verweij J, Van Glabbeke M, van Oosterom AT, Christian MC, et al: New guidelines to evaluate the response to treatment in solid tumors. European Organization for Research and Treatment of Cancer, National Cancer Institute of the United States, National Cancer Institute of Canada. J Natl Cancer Inst 92: 205-216, 2000.

24. Raghav K and Overman MJ: Small bowel adenocarcinomas-existing evidence and evolving paradigms. Nat Rev Clin Oncol 10: 534-544, 2013.

25. Kawakami K, Salonga D, Park JM, Danenberg KD, Uetake H, Brabender J, Omura K, Watanabe G and Danenberg PV: Different lengths of a polymorphic repeat sequence in the thymidylate synthase gene affect translational efficiency but not its gene expression. Clin Cancer Res 7: 4096-4101, 2001.

26. Iacopetta B, Grieu F, Joseph D and Elsaleh H: A polymorphism in the enhancer region of the thymidylate synthase promoter influences the survival of colorectal cancer patients treated with 5-fluorouracil. Br J Cancer 85: 827-830, 2001.

27. Marsh S, McKay JA, Cassidy J and McLeod HL: Polymorphism in the thymidylate synthase promoter enhancer region in colorectal cancer. Int J Oncol 19: 383-386, 2001.

28. Etienne MC, Chazal M, Laurent-Puig P, Magné N, Rosty C, Formento JL, Francoual M, Formento P, Renée N, Chamorey E, et al: Prognostic value of tumoral thymidylate synthase and $\mathrm{p} 53$ in metastatic colorectal cancer patients receiving fluorouracilbased chemotherapy: Phenotypic and genotypic analyses. J Clin Oncol 20: 2832-2843, 2002.

29. Tsuji T, Hidaka S, Sawai T, Nakagoe T, Yano H, Haseba M, Komatsu H, Shindou H, Fukuoka H, Yoshinaga M, et al: Polymorphism in the thymidylate synthase promoter enhancer region is not an efficacious marker for tumor sensitivity to 5-fluorouracil-based oral adjuvant chemotherapy in colorectal cancer. Clin Cancer Res 9: 3700-3704, 2003.
30. Overman MJ, Pozadzides J, Kopetz S, Wen S, Abbruzzese JL, Wolff RA and Wang H: Immunophenotype and molecular characterisation of adenocarcinoma of the small intestine. Br J Cancer 102: 144-150, 2010

31. Aparicio T, Svrcek M, Zaanan A, Beohou E, Laforest A, Afchain P, Mitry E, Taieb J, Di Fiore F, Gornet JM, et al: Small bowel adenocarcinoma phenotyping, a clinicobiological prognostic study. Br J Cancer 109: 3057-3066, 2013.

32. Nishiyama K, Yao T, Yonemasu H, Yamaguchi K, Tanaka M and Tsuneyoshi M: Overexpression of $\mathrm{p} 53$ protein and point mutation of K-ras genes in primary carcinoma of the small intestine. Oncol Rep 9: 293-300, 2002.

33. Santini D, Fratto ME, Spoto C, Russo A, Galluzzo S, Zoccoli A, Vincenzi B and Tonini G: Cetuximab in small bowel adenocarcinoma: A new friend? Br J Cancer 103: 1305, author reply 1306, 2010.

34. De Dosso S, Molinari F, Martin V, Frattini M and Saletti P: Molecular characterisation and cetuximab-based treatment in a patient with refractory small bowel adenocarcinoma. Gut 59: 1587-1588, 2010.

35. Wang YC, Xue HP, Wang ZH and Fang JY: An integrated analysis of the association between Ts gene polymorphisms and clinical outcome in gastric and colorectal cancer patients treated with 5-FU-based regimens. Mol Biol Rep 40: 46374644, 2013.

36. Park CM, Lee WY, Chun HK, Cho YB, Yun HR, Heo JS, Yun SH and Kim HC: Relationship of polymorphism of the tandem repeat sequence in the thymidylate synthase gene and the survival of stage III colorectal cancer patients receiving adjuvant 5-flurouracil-based chemotherapy. J Surg Oncol 101: 22-27, 2010.

37. Aschele C, Debernardis D, Casazza S, Antonelli G, Tunesi G, Baldo C, Lionetto R, Maley F and Sobrero A: Immunohistochemical quantitation of thymidylate synthase expression in colorectal cancer metastases predicts for clinical outcome to fluorouracil-based chemotherapy. J Clin Oncol 17: 1760-1770, 1999.

38. Johnston PG, Benson AB III, Catalano P, Rao MS, O'Dwyer PJ and Allegra CJ: Thymidylate synthase protein expression in primary colorectal cancer: Lack of correlation with outcome and response to fluorouracil in metastatic disease sites. J Clin Oncol 21: 815-819, 2003.

39. Popat S, Matakidou A and Houlston RS: Thymidylate synthase expression and prognosis in colorectal cancer: A systematic review and meta-analysis. J Clin Oncol 22: 529-536, 2004.

40. Qiu LX, Tang QY, Bai JL, Qian XP, Li RT, Liu BR and Zheng MH: Predictive value of thymidylate synthase expression in advanced colorectal cancer patients receiving fluoropyrimidine-based chemotherapy: Evidence from 24 studies. Int J Cancer 123: 2384-2389, 2008. 